\title{
Attitudes of American Teachers Preparing to Become Administrators toward Teaching Creative Strategies
}

\author{
Climetine Clayburn, Stu Ervay, Nancy Albrecht \\ Department of School Leadership/Middle and Secondary Teacher Education, \\ Emporia State University, Emporia, USA \\ Email: cclaybur@emporia.edu
}

Received October $30^{\text {th }}, 2011$; revised November $24^{\text {th }}$, 2011; accepted December $10^{\text {th }}, 2011$

\begin{abstract}
This article presents findings of a study to determine attitudes of American teachers enrolled in graduate human relations and supervision and teacher evaluation courses taken as part of a program preparing them to become school administrators. They were given instruction on the New Bloom's Taxonomy and asked to consider the Bill of Rights for the Planet as a possible catalyst for the teaching of creativity; they were then asked to provide their re-actions to these guiding research questions: 1) To what extent are currently mandated or suggested curriculums allowing the teaching of creativity in their respective grade levels or subjects? 2) How would they assist teachers under their supervision, once becoming administrators, to structure local curriculums and lessons to include the teaching of creative solutions to issues? Sub-research questions included: 1) How would you define creativity in teaching? 2) What do you consider to be barriers to creativity? 3) As a future school administrator, what do you anticipate you will do to enhance creativity in your building? Based on their responses to the previous mentioned prompts, it was concluded that teachers are not using creativity to a high level in their currently mandated or suggested curriculums. There was strong indication that these future administrators felt that it was part of their responsibility to make sure their teachers used creativity in the classroom. To have creativity there needs to be a foundation to build upon and the willingness of teachers to accept more than one answer for a problem.
\end{abstract}

Keywords: Creative Teaching Strategies; Administrator Training

\section{Introduction}

There is growing concern that America, the best educated nation in the world a generation ago, may be lagging behind nine other countries in college completion. As President Barack Obama stated in the publication, A Blueprint for Reform, "It is not that their students are smarter than ours. It is that these countries are being smarter about how to educate their students” (United States Department of Education, 2010). The Reauthorization of the Elementary and Secondary Act by the United States Congress is still pending. However, the United States Department of Education recently and boldly promoted world-class education as a prerequisite for success. That position statement asserts that every student must graduate from high school and be well prepared for college and a career. It is hoped that any congressional reauthorization of NCLB (No Child Left Behind), or creation of a new process, will contain similar language.

The original NCLB was designed to increase teacher accountability and improve student learning, and caused standardized testing to assume a prominent role in educational reform efforts. It seems what has become most important is passing state standardized tests. Meeting narrowly defined educational goals is causing teachers to view student curiosity as frivolous and even a supplemental task. "An overwhelming complaint among teachers is that inflexible, prescribed curriculums do not allow instructional time to peak student curiosity and creativity, nor do they allow teachers to seek student input regarding what they learn,” (Engel \& Randall, 2009: p. 183). Clearly, inclusion of creativity in the curriculum is no longer considered a high priority.

Most recently, a growing concern regarding standardized testing and increased accountability was made public when USA Today related that, "Ten states now use test scores as the main criterion in teacher evaluations. Other states reward highscoring teachers with up to $\$ 25,000$ bonuses-while low scores could result in principals losing their jobs or entire schools closing.” This was revealed in the unfolding of America's biggest teacher and principal cheating scandal in Atlanta where it was reported, "At least 178 teachers and principals in Atlanta Public Schools cheated to raise student scores on high-stakes standardized tests, according to a report to a report from the Georgia Bureau of Investigation.” Furthermore, USA Today stressed, "This appears to be the largest of dozens of major cheating scandals, unearthed across the country. The allegations point to ongoing problems for US education, which has developed an ever-increasing dependence on standardized tests" (USA Today, 2011). Similar concerns have been expressed by researchers in even more recent years, "State assessments can steer even the most skilled teachers down the wrong path as they deliver instruction,” (Longo, 2010: p. 54)

Given the recent national emphasis on standards and the use of high stakes tests, American teachers preparing to become school administrators may not have positive attitudes toward teaching creative strategies. They most likely will conclude that, as administrators, they will be held accountable primarily for how well students perform on summative tests that are based either on state standards or the new national Core Standards being adopted by most states. With so much emphasis on stan- 
dards, they may not be acquainted with the New Bloom's Taxonomy that places creating at the top of the learning hierarchy, nor are they likely to be aware of why that action was taken. Another problem may be they don't really understand how to teach creativity as it is unformulated and difficult to define. The teaching of creativity has to be put into a more tangible context that can be easily interpreted and practiced, and relative to students' lives to become an important element of teaching for critical thinking. One framework credited with promoting the concept of creativity in real world meaning is through a resurgence of constructivism. The principles of constructivist teaching and learning include integration of content and collaborative practices for creating new knowledge.

As a precursor to the conduct of this research, study subjects were provided information on the New Bloom's Taxonomy. Giving subjects participating in the study baseline information about the new perspectives was critical to later receiving insightful responses to these two guiding prompts: 1) To what extent are currently mandated or suggested curriculums allowing the teaching of creativity in their respective grade levels or subjects? and 2) How would they assist teachers under their supervision, once becoming administrators, to structure local curriculums and lessons to include the teaching of creative solutions to issues?

Those participating in the study were currently enrolled, or had been enrolled within the past two years in a required graduate human relations or supervision and teacher evaluation course conducted online by Emporia State University as well as students who have taken the course in the past two years, and included forty-seven (47) teachers, counselors, and instructional coaches currently working in Kansas, Missouri, Mississippi, Ohio, Oklahoma, and Texas. The vast majority were working in Kansas. The study was conducted in the fall semester of 2010 and spring semester of 2011.

\section{Description of the New Bloom's Taxonomy}

Benjamin Bloom's original Taxonomy of Cognitive Domain was published in 1956. Commonly referred to as "Bloom's Taxonomy," it has been translated into 22 languages, and is one of the most widely used references in education. In the 1990's, one of Bloom's former students, Lorin Anderson, headed up a new group of educational theorists and researchers to review and update the original taxonomy. After six years of work, the revision was published in 2001. Since then, many educators have traded in their "old" version of Bloom for the newer version. However, they certainly do not represent a majority of the teaching profession. There are still countless educators who are not aware that an update exists, and a like number who know about the new version, but aren't sure what to do with it.

First, what exactly has changed? There are three overall differences: terminology, structure, and emphasis. The one gathering attention from most educators is terminology, and that is the one we focus on here. (A web search about the revised taxonomy will provide many sites if you want to know more about the structure and emphasis.) Within the terminology changes there are also three differences: 1 ) some of the categories of the taxonomy were renamed; 2) all of the category names were changed from nouns to verbs; and 3) synthesis and evaluation (now evaluating and creating) changed places on the pyramid. Figure 1 provides a graphic representation of those changes.

Definitions of the new terms are similar to those most widely used with the older version, with a few differences:

Remembering: Retrieving, recognizing, and recalling relevant knowledge from long-term memory.

Understanding: Constructing meaning from oral, written, and graphic messages through interpreting, exemplifying, classifying, summarizing, inferring, comparing, and explaining.

Applying: Carrying out or using a procedure through executing, or implementing.

Analyzing: Breaking material into constituent parts, determining how the parts relate to one another and to an overall structure or purpose through differentiating, organizing, and attributing.

Evaluating: Making judgments based on criteria and standards through checking and critiquing.

Creating: Putting elements together to form a coherent or functional whole; reorganizing elements into a new pattern or structure through generating, planning, or producing, (Anderson, Krathwohl et al., 2001).

This new version should be used in the same way as the previous taxonomy - to guide the development of curriculum, inform instructional practices, and direct the wording of assessments. These "uses" are what are most important to help assure that teaching and learning go beyond rote memory and the "lower" levels of thinking, to include higher levels. Two other things to keep in mind: 1) all ages of student can achieve high levels of thinking; and 2) a single activity or assignment can include multiple kinds of thinking skills. Table 1 provides an example that covers all six of Bloom's categories using the old and new version (Roach, 2008).

\section{Rationale for a Constructivism Resurgence to Stimulate the Teaching of Creativity}

Teaching that promotes learning shares these identifiable characteristics: 1) emphasizes thinking and problem-based learning; 2) permits student choice and initiative, and 3) encourages depth over breadth. It is well documented that high-level learning requires high-level instruction. Researchers are calling for a constructivism resurgence to refocus instruction for creativity. This approach stems from the writings of Dewey, Vygotsky, Piaget, and valued foundations in cognitive psychology. "While it was not collectively accepted in the $20^{\text {th }}$ century, it is now recognized by cognitive psychologists as offering the most powerful scaffolding to understand how children and adults learn,” (Danielson, 2007). In Table 2 an example of a constructivist teaching using the New Bloom's Taxonomy is provided.

Constructivism seem to be a promising approach to creativity in the classroom because it calls for both social (or collaborative) learning and integrated instruction that causes students to

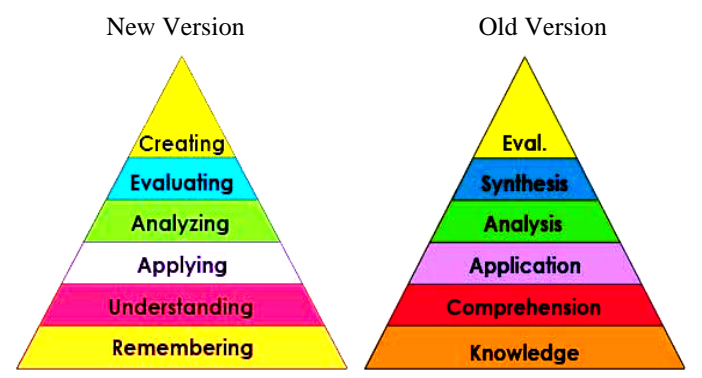

Figure 1.

Representation of new and old bloom's taxonomy. 
engage in problem solving and to create their own understanding of knowledge. "A key element in collaborative learning is its epistemological perspective that knowledge is socially constructed, created by communities rather than individuals. knowledge is not poured into students but rather emerges from ongoing dialogue and social interaction among groups," (Austin \& Baldwin, 1991, pp. 14-15). The emergence of creating new knowledge through dialogue with peers was explained in the Fifth Discipline (1990) by Peter Senge. He calls for "a shift of mind-from seeing ourselves as separate from the world to connected to the world, from seeing problems as caused by someone or something 'out there' to seeing how our own actions create the problems we experience. A learning organization is a place where people are continually discovering how they create their reality. And how they can change it” (pp. 12-13).

An example of a learning organization within schools is a "professional learning community" (PLC). It is what happens when faculty study, plan, and work together to collectively increase student learning through creativity. PLCs can produce positive outcomes for teachers and students. Such outcomes include: creating shared responsibility for the total development of students, enhancing curriculum and greater understanding of teacher responsibilities, creating powerful learning that defines high-level teaching, reducing teacher isolation, increasing

Table 1.

Example using new and old versions of bloom's taxonomy.

Jack and the Beanstalk

\begin{tabular}{lll}
\hline \multicolumn{1}{c}{ Old Term } & New Term & \multicolumn{1}{c}{ Action } \\
\hline $\begin{array}{l}\text { Knowledge } \\
\text { Comprehension } \\
\text { Application }\end{array}$ & $\begin{array}{l}\text { Remembering } \\
\text { Understanding } \\
\text { Applying }\end{array}$ & $\begin{array}{l}\text { Where did Jack get the beans? } \\
\text { Illustrate the story. } \\
\text { List at least two crimes Jack may have } \\
\text { committed. }\end{array}$ \\
Analysis & Analyzing & $\begin{array}{l}\text { Find one or more differences between } \\
\text { Jack's earlier and later behavior. }\end{array}$ \\
Evaluation & Evaluating & $\begin{array}{l}\text { Do you think Jack's actions were } \\
\text { justified? Why or why not? } \\
\text { Create a mock trial in which Jack is } \\
\text { Synthesis }\end{array}$ \\
\hline
\end{tabular}

Table 2.

Constructivist teaching using new bloom's taxonomy.

\begin{tabular}{cl} 
A Civil War Unit in Secondary Education \\
\hline Remembering & $\begin{array}{l}\text { Make a timeline of major battles and indicate which } \\
\text { side won each battle? } \\
\text { Understanding }\end{array}$ \\
& $\begin{array}{l}\text { Write a letter home as if you were a soldier fighting in } \\
\text { a major battle and include description about the } \\
\text { weather that day, the terrain, what you ate, sleeping } \\
\text { conditions and your clothing, the welfare of your } \\
\text { buddies, events of the battle. }\end{array}$ \\
Applying & $\begin{array}{l}\text { Discuss the subsequent events of the battle you } \\
\text { described and how they affect the overall landscape } \\
\text { of the war. }\end{array}$ \\
Analyzing & $\begin{array}{l}\text { What were the differences in the people, land, } \\
\text { economy, and morale of the country in North and the } \\
\text { South at the onset and the end of the war? } \\
\text { Break into two groups with one being affirmative and } \\
\text { one being negative, debate whether The Civil War } \\
\text { was necessary or not? } \\
\text { Create a modern civil war. Determine the cause for } \\
\text { the war and how this war will impact other counties } \\
\text { of the world. What consequences and benefits would } \\
\text { there be? }\end{array}$ \\
\hline
\end{tabular}

commitment to the mission, vision, and goals of the school, and securing a program for ongoing learning. Teachers who participate in such learning communities are more apt to create them in their classrooms. By nature, they lend themselves to constructivist teaching.

The other, integrated instruction helps students develop critical thinking skills that they will use to improve the world in which they live. It encourages students to become curious in their learning as they seek creative solutions to multifaceted issues by making unconventional connections between and among disciplines. "As students see how the content of one course relates to that of others, they begin to make connections, and in doing so gain not only a more integrated view of the knowledge, but also a more authentic view of life" (Boyer, 1987, p. 92). It is through acts of creativity that we develop important human capacities that benefit self and society.

\section{Description of the Bill of Rights for the Planet}

The Bill of Rights for the Planet was created by architects who are obviously interested in the whole field of design, which marries the practical aspects of life to artistic interpretations. What makes the list so interesting in the realm of teaching and learning is that it calls for an improved kind of human interaction with the environment, making it an inherent part of every subject in school. It doesn't take much imagination to see how science, mathematics, language arts and social studies are represented. The same is true of all fine and practical arts subjects, as well as physical education and wellness. A review of the nine principles can cause one to see the relationship quickly:

1) Insist on the right of humanity and nature to co-exist in a healthy, supportive, diverse, and sustainable condition.

2) Recognize Interdependence. The elements of human design interact with and depend on the natural world, with broad and diverse implications at every scale. Expand design considerations to recognizing even distant effects.

3) Respect relationships between spirit and matter. Consider all aspects of human settlement including community, dwelling, industry, and trade in terms of existing and evolving connections between spiritual and material consciousness.

4) Accept responsibility for the consequences of design decisions upon human well-being, the viability of natural systems, and their right to co-exist.

5) Create safe objects of long-term value. Do not burden future generations with requirements for maintenance or vigilant administration of potential danger due to the careless creations of products, processes, or standards.

6) Eliminate the concept of waste. Evaluate and optimize the full life-cycle of products and processes, to approach the state of natural systems in which there is no waste.

7) Rely on natural energy flows. Human designs should, like the living world, derive their creative forces from perpetual solar income. Incorporate this energy efficiently and safely for responsible use.

8) Understand the limitations of design. No human creation lasts forever and design does not solve all problems. Those who create and plan should practice humility in the face of nature. Treat nature as a model and mentor, not an inconvenience to be evaded or controlled.

9) Seek constant improvement by the sharing of knowledge. Encourage direct and open communication between colleagues, patrons, manufacturers and users to link long term sustainable considerations with ethical responsibility, and re-establish the 
integral relationship between natural processes and human activity.

\section{Rationale for Using the Bill of Rights for the Planets}

The rationale for using the Bill of Rights for the Planet as a study prompt was to provide subjects with a specific cognitive set of which they could imagine student learning outcomes, lessons and classroom activities. For example, the second point in the Bill of Rights mentions broad and diverse implications with regard to human interactions with the natural world. Clearly, a statement like that rejects the notion that there is only one way for human beings to structure cities or neighborhoods, so an interesting scenario can be established that-given the needs of particular human communities - cities might be organized differently to meet those needs. Curricular scenarios like that call for interdisciplinary (integrated) programs of study in which statistics, pollution control systems, media organizations, and anthropological perspectives are mixed with human wellness considerations and aesthetics.

\section{Strategy for Eliciting Responses from Teachers Preparing to Become School Administrators}

Subjects in the study, after receiving an opportunity to consider and study the ramifications of the New Bloom's Taxonomy (as seen in the Bill of Rights for the Planet prompt), were asked to extrapolate ideas found in those processes and generate viewpoints through responses to the following questions:

1) To what extent are currently mandated or suggested curriculums allowing the teaching of creativity in their respective grade levels or subjects?

2) How would they assist teachers under their supervision, once becoming administrators, to structure local curriculums and lessons to include the teaching of creative solutions to issues?

4) How would you define creativity in teaching?

5) What do you consider to be barriers to creativity?

6) As a future school administrator, what do you anticipate you will do to enhance creativity in your building?

\section{Results from the Survey of Teachers}

The survey first focused on the new Bloom's Taxonomy published in 2001; while the second part sought to understand the meaning of creativity and how it can be implemented into teaching and learning.

\section{General Information}

The majority of survey participants were classroom teachers with an even distribution between elementary and secondary (middle and high school); counselors and instructional coaches were also part of this study. One participant had been laid off due to budget cuts. Fifty-one percent were working in what they described as a suburban environment, followed by $28 \%$ percent were working in an urban area. The largest number of participants worked in districts with an enrollment of 1201 or more students, and the majority live in Kansas.

\section{Survey-Focus One}

The researchers had no preconceived ideas but did realize that when most educators are asked about the use of Bloom's Taxonomy they will report using the elements at the bottom (Remembering, Understanding, and Applying) more often than those listed at the top of the pyramid. That was also the case in this study. Remembering, Understanding, and Applying were used most frequently in subjects identified as currently critical to meeting adequate yearly progress (AYP) for the individual's school.

It was reported that if there wasn't the pressure to meet AYP, then an emphasis on Creating would be used more frequently. One participant stated that "the most frequently used element is to make sure that students remember the subject matter." Another stated that "rote memory is important for basic information when it comes to testing." Other student comments associated with the three bottom levels of Bloom's Taxonomy were these:

\section{Remembering}

- "Remembering is highly important for assessments."

- "Remembering must be used to prepare for NCLB tests."

\section{Understanding}

- "It lets me know if the students are 'getting' the information."

- "It is the basic level that is foundation for other learning."

- "An ability to review data and distinguish the important information is essential."

- "Understanding certain concepts is also important for testing."

\section{Applying}

- "If students can apply the information, they have mastered it."

- "The application is really what makes this all worthwhile. Why learn something in school if you are never going to apply it anywhere?"

- "Applying is highly important for assessments."

- "Applying is also necessary for the NCLB [No Child Left Behind] tests."

Those who reported giving attention to Evaluating and Creating very frequently were only fourteen percent of the total respondents. Those students indicated that using strategies found at the top of the pyramid would actually help students be better prepared to take state assessments.

Eighty-six percent of those reporting felt that Creating should be at the top of Bloom's Taxonomy as it relates to student learning. However, $55 \%$ of those reporting said they had a problem when teaching using this learning objective. Seventy-three percent indicated that the Creating element actually includes all the other categories in Bloom's Taxonomy. When asked if as a future administrator they had a responsibility to work with the teachers in the building or district to enhance the teaching and learning of creativity, $86 \%$ responded with a yes, while $14 \%$ said "maybe" and no one reported with an answer of "no".

\section{Survey-Focus Two}

Regarding how future administrators would define creative in teaching, many comments were favorable and indicated that it encourages higher-level thinking. Examples of these responses were: 
- "I believe that creativity is being able to express your ideas freely without feeling intimidated by what others may think. We all have different gifts and talents and should be able to problem solve and think creatively considering multiple ideas on how to solve a problem. The freedom to be creative also allows a person to retain their individualism while hearing others' ideas at the same time. Many times our own creativity is enhanced when we hear and share out and exchange our ideas with others."

- "Creativity is finding a unique way to do something or to solve a problem. As a teacher, creativity is one key in keeping students engaged in the classroom. As a building administrator, it is a key to keeping staff engaged in the school."

- "Creativity is being yourself and coming up with solutions to problems by doing your own thinking. I think it also includes being bold enough to use the solution you came up with."

However, one participant wrote that "[you] can teach and insist on many different things; however you cannot teach creativity [because] it is something that comes from within." Another student wrote that: "[it's] a very foreign way of thinking for today's classroom teacher.”

Responses of study participants who thought a curriculum that emphasizes creative teaching and learning must incorporate interdisciplinary (integrated) configurations (connecting currently separate subjects) was $66 \%$ - “yes" and $27 \%$ - “maybe”. One participant wrote, "I think many subjects can be integrated without much work at all. I think that those [who] think it takes a lot of work to integrate thing[s], don't see the big picture. If you are reading a science text, one is already incorporating reading and comprehension of the material. If there are any charts or graphs then you [use] math skills. If there is a map of the universe you already have social studies...” Others wrote that "few things can be taught in isolation; each subject... relates to another; to prepare students for the future... we have to link subjects together in some fashion;" and "interdisciplinary units... allow for students to use new-found information and ideas in different ways." Eighty-nine percent indicated either "yes" or "maybe" that they could see using the Bill of Rights for the Planet as a catalyst to enhance the teaching of creativity. One respondent wrote, “It covers all of the areas of Bloom's levels. The words used are some of the very words used in the six levels, new and old." Another wrote that there was an appreciation for "the idea of allowing or accepting humanity and nature to co-exist."

Seventy-three percent of those participating in this survey felt that the current American school system would need to be changed if the focus of instruction employed more than a moderate degree of teaching and learning for creativity. Someone wrote that "[the] American system does not necessarily [have] to change, but the way teaching is done might have to change." Some needs that were mentioned to teach creatively included less emphasis on assessments, less government control, and not being considered just another add on. All of those completing the survey indicated with a Yes (55\%) or Maybe (45\%) response that this is a good direction for the nation to take. Eighty-six percent did think that, as future administrators, one of their responsibilities included the need to work with the teachers in the building and/or district to enhance the teaching and learning of creativity.

\section{Conclusion}

We know that students who are actively engaged in learning for deeper understanding are more likely to learn more than students not so engaged. The information collected suggests that current mandated or suggested curriculums are not using the teaching of creativity in their respective grade levels or subjects. Reasons given were lack of time, focus on state assessments, and not actually knowing how creativity would look in their subject area.

The future administrators included in this study, who often have difficulty teaching creative concepts, felt that it was part of their responsibility to ensure their teachers used creativity in the classroom. For creativity to be part of an instructional program there needs to be a foundation to build upon, and the willingness of teachers to accept more than one answer/solution for a problem.

\section{Implications}

1) For creating to be part of the American educational system teachers and administrators must be knowledgeable of how to use this area in the different content areas.

2) A resurgence of constructivism will need to be initiated into the school's mission, vision, and goals by administrators and teachers to encourage creative instruction and learning in classrooms.

3) Administrators will need to provide resources and supports for the forming of professional learning communities (PLCs) to increase teacher professional development and creative teaching and student learning.

4) Teachers will need to understand and be held accountable for the integration of instruction.

5) For these items to work, changes must be made in the preparation of teachers and administrators, with a collateral paradigm shift in the schools that employ them. For that paradigm shift to take place, the current emphasis on rigid testing procedures that focus on the lower levels of Bloom's Taxonomy must be greatly modified.

\section{Acknowledgements}

We extend our appreciation to the former and present students enrolled in educational leadership classes, as well as colleagues who assisted with collection of information from previous students.

\section{REFERENCES}

Anderson, L. W., Krathwohl, D. R., Airasian, P. W. \& Cruikshank, K. L. (2000). A Taxonomy for learning, teaching and assessing: A revision of bloom's taxonomy of educational objectives. Boston, MA (Pearson Education Group): Allyn \& Bacon.

Austin, A., \& Baldwin, R. (1991). ASHE ERIC Higher Education Report No.71. Faculty collaboration: Enhancing the quality of scholarship and teaching. Washington DC: University of Washington DC. School of Education and Human Development.

Boyer, E. (1987). College: The undergraduate experience in America. New York: Harper and Row.

Climetine, C., Ervay, S., \& Albrecht, N. (2010). Survey information.

Danielson, C. (2007). Enhancing professional practice: A framework for teaching. Alexandria, VA: Association for Supervision and Curriculm Development.

Department of Education. (2010). A blueprint for reform. Washington 


\section{CLAYBURN ET AL.}

DC: United States Department of Education.

Engel, S., \& Randall, K. (2009). How teachers respond to children's inquiry. American Educational Research Journal, 46, 183-202.

Leff, H., \& Gordon, L. (1979). Environmental cognitive sets: A longitudinal study. Environmental Behavior, 11, 291-327. doi:10.1177/0013916579113001

Longo, C. (2010). Fostering creativity or teaching to the test? Implications of state testing on the delivery of science instruction. Clearing House, 83, 54-57. doi:10.1080/00098650903505399
McDonough, W., \& Partners. (2000). The hannover principles: Design for sustainability. Hanover: The World's Fair.

Roach, C. (2010). Curriculum leadership institute e-hint. Emporia, KS: Curriculum Leadership Institute. URL (last checked September 2008). http:www.cliweb.org/Ehintstc/CI8.pdf

Senge, P. (1990). The fifth discipline: The art of the learning organization. New York: Currency Doubleday.

USA Today. (2011) America's biggest teacher and principal cheating scandal unfolds in Atlanta. 8 July 2011. 